\title{
Formação de professores na perspectiva da inclusão escolar da pessoa com deficiência: um estudo bibliográfico
}

\author{
Natália Macedo Nunes*
}

\begin{abstract}
Resumo
O estudo tem como tema a formação profissional na perspectiva da inclusão de pessoas com deficiência no ambiente escolar. A luta desse grupo caracterizou qualitativamente o trabalho, levando em consideração a subjetividade, valores e crenças. Dessa forma, foi realizada uma pesquisa bibliográfica na qual utilizamos como paradigma o materialismo dialético para encontrar respostas à problemática da pesquisa. Dessa forma, temos como objetivos estudar as competências necessárias ao profissional que trabalha com a inclusão, apresentar princípios que norteiam a formação profissional, destacar fatores que influenciam a forma como a inclusão é pensada, investigar a relação da inclusão com a Educação Física e, finalmente, descrever alguns desafios encontrados pela inclusão nas instituiçóes escolares. Constatou-se que pouco tem sido o investimento e o interesse dos órgãos públicos com o bem-estar desse grupo, ou seja, sem um compromisso político e financeiro com o sistema educacional, pouco pode ser mudado. A ausência de informação ainda na formação inicial dos profissionais também foi um fator de destaque para esta pesquisa, na medida em que se levantou a importância da constante formação e a capacitação profissional. Assim, pretendemos aprofundar os estudos sobre a educação inclusiva, pois acreditamos que o processo de conscientização acerca da inclusão social e educacional se efetivará por meio da união dos participantes da sociedade. Palavras-chave: inclusão escolar, educação física, formação profissional.
\end{abstract}

Teacher formation from the perspective of inclusion of the disabled: a bibliographical study

\section{Abstract}

The theme of this study is vocational formation from the perspective of including the disabled in the school environment. This study was qualitatively characterized by the struggle of this group, taking into account subjectivity, values and beliefs. A literature search was undertaken

* Licenciada em Educação Física pela Universidade Federal de Goiás (UFG), especialista em Educação Física Escolar pela Universidade Estadual de Goiás (UEG). Professora substituta do Centro de Ensino e Pesquisa Aplicada à Educação da Universidade Federal de Goiás (Cepae-UFG). E-mail: natmacedonunes@hotmail.com. 
in which dialectical materialism was used as a paradigm to come up with answers to the research problem. The study set out to analyze the skills needed by professionals working with inclusion, present the principles which underlie vocational formation, highlight factors which influence how inclusion is thought out, investigate the relationship between inclusion and $\mathrm{PE}$, and finally, describe the challenges which inclusion presents for the school. It was found that there has been little investment or interest on the part of public authorities in the welfare of this group. In other words, without political and financial commitment to the educational system little can be changed. The lack of information at the initial formation phase of professionals was also a major factor for this research, as was awareness of the importance of ongoing formation and professional training. Consequently, the authors intend to undertake further study on inclusive education as they believe that the process of awareness of social and educational inclusion will be brought about through the united efforts of society participants. Keywords: school inclusion, physical education, vocational formation.

\section{Introdução}

estudo tem como tema investigar a formação de professores para trabalharem com a inclusão de pessoas com necessidades educativas especiais. Tem o intuito, ainda, de sistematizar conhecimentos teóricos, assim como apresentar conteúdos para se pensar sobre o que pode ser desenvolvido nessa realidade.

Apresentaremos um pouco da história das pessoas com necessidades especiais na instituição escolar, apoiados em leis e documentos oficiais que defendem seus direitos. Partiremos de alguns acontecimentos internacionais, como a Declaração de Salamanca e os Direitos Humanos que dialogam sobre os direitos universais, porém sabe-se que o discurso de que todos são iguais é falho, na medida em que não conseguem igualar os ditos "normais" diante das diferentes condiçóes sociais.

Os marcos internacionais influenciaram diretamente os eventos nacionais, que se baseavam nas determinaçóes que os documentos internacionais propunham. Percebe-se, assim, o grande objetivo, que é conseguir com que os países de terceiro mundo seguissem as determinaçóes que eles elencavam como as mais coerentes. No nosso país, encontramos leis que apoiam a criança com deficiência na escola, porém existem dificuldades na instituição pública que perpassam todo o ensino, seja ela para uma criança com necessidades especiais ou não.

Por fim, queremos destacar os desafios da inclusão no sistema educacional, seus objetivos e evolução, buscando a inclusão dessas crianças especiais. Dentro da escola, focamos ainda na Educação Física, que desde o processo 
da industrialização tem modificado suas concepçóes. Para tanto, analisar e refletir sobre a relação da inclusão com a Educação Física é o primeiro passo para o diálogo inclusivo. $\mathrm{O}$ estudo apresentará, por meio de documentos e materiais teóricos, como a inclusão vem sendo pensada e discutida na ótica internacional e nacional, bem como no campo da Educaçáo Física.

Esperamos, com este estudo, contribuir, mesmo que indiretamente, com os alunos na busca de melhorias para a educaçáo. É importante destacar que esse grupo conseguiu conquistar seu espaço nas discussóes internacionais, não por interesse dos governantes, mas, sim, por sua luta em busca de melhores condições de vida.

O trabalho é de natureza qualitativa, porque esse tipo de análise possibilita a compreensão das singularidades do fenômeno social, que tem como objeto de estudo as situaçóes complexas e/ou particulares que somente o método quantitativo não consegue analisar (MENDONÇA; ROCHA; NUNES, 2008). A pesquisa é bibliográfica, pois será desenvolvida a partir de leituras e análises de diversas fontes teóricas acerca de um problema determinado por um tema, ou seja, é uma consulta de materiais já produzidos e sistematizados, de domínio público e com valor científico (MENDONÇA; NUNES, 2003). Utilizamos como paradigma o materialismo dialético para encontrar respostas à problemática da pesquisa. Esse paradigma mostrou-se mais eficaz, pois consideramos a dialética a metodologia mais conveniente para analisar a realidade social, na medida em que se trata de um pressuposto ontológico, com a necessidade de desenvolver um fenômeno histórico ao lado da consciência reflexa, da ideologia e da qualidade política (DEMO, 1995).

Dessa forma, levantamos como questionamento a discussão acerca das competências necessárias ao profissional que desenvolve seu trabalho na perspectiva inclusiva. Citamos como exemplo o pouco conhecimento na formação profissional para lidar com os alunos que possuem necessidades educativas especiais, visto que, muitas vezes, esse conhecimento é negado ou mesmo ignorado, por usarem o senso comum ao tratar dessa realidade.

\section{A pessoa com deficiência e a legislaçáo}

O corpo é um objeto de conhecimento e intervenção, que se projeta em construção humana. Ele é, segundo Soares (2000, p. 46), "um conjunto de forças capaz de por em movimento determinaçóes precisas, conter e reprimir 
desejos, preservar energia”. A ginástica traz para o corpo conhecimentos como a postura, a retidão e a consciência da posição do corpo no espaço. Dessa forma, ela sofre influências das determinaçóes militares, que incidem sobre o corpo por meio de algumas açóes pedagógicas. Os corpos deveriam apresentar-se em uma normalidade útil e, desde a infância, a retidão era o norte da educação das crianças. A ginástica ainda sofre influências da Antiguidade e do Renascimento, que impregnaram a ideia do corpo limpo e civilizado.

A partir do século XIX, as teorias higienistas tornaram-se dominantes, com tendências moralizadoras e adaptadas às determinaçóes médicas. $\mathrm{O}$ pensamento e a medicina higienista influenciaram diretamente a sociedade e sua forma de organização, retardando a compreensão do homem como um ser social, cuja humanidade se constitui na vida em sociedade (SOARES, 2000).

Partindo de um novo modelo, o mecanicista, produz-se um conjunto de teorias que justificam as diferenças sociais por meio das diferenças biológicas. Dessa forma, devido à necessidade de a sociedade capitalista ocupar postos de trabalho, as aptidóes eram naturalmente destacadas. Nesse sistema de enaltecimento das aptidóes físicas, a pessoa com deficiência encontrava-se excluída de qualquer função na sociedade instaurada, pois o que governava era um corpo perfeito (motor e mental) para desempenhar produtivamente o papel que lhe fosse instituído, realidade distante de qualquer pessoa que possui alguma deficiência (SOARES, 2000).

Jannuzzi (2004) descreve que, em meados da década de 1980, quando se tratava de pessoas com necessidades especiais, já se vislumbrava sua deficiência nítida, ou seja, a ênfase estava no que faltava a essa pessoa. Com a industrialização, veio a preocupação de garantir que o deficiente, até então isolado, se tornasse produtivo. No fim de 1970 e início de 1980, surge a "normalização", que busca modificar o deficiente para a sociedade, dando condiçóes de vida semelhantes à de uma pessoa comum. É importante ressaltar que foi na década de 1950 que os deficientes começaram a se organizar para conseguirem participação no que se referia às discussóes de seus problemas. E assim surgem entidades, conselhos, organizaçóes que lutavam e lutam para garantirem seus direitos.

Adotando como ponto de partida alguns movimentos internacionais, Oliveira (2004) analisa documentos como o Programa de Ação Mundial para Pessoas Deficientes (1982), a Declaração Mundial sobre Educação para Todos (JOMTIEM, 1990) e a Declaração de Salamanca (1994). Segundo o autor, esses eventos internacionais 
reúnem representantes de governos, organismos internacionais e bilaterais de desenvolvimento de organizaçóes não-governamentais da maioria dos países do mundo. Neles, produz-se uma série de documentos sob a forma de declaração de intençôes, programas e planos de ação mundial que, por sua vez, servem como vetores de orientação para a definição de políticas educacionais nacionais, inclusive e, especialmente, nos países do chamado Terceiro Mundo. (OLIVEIRA, 2004, p. 209-10)

A Conferência Mundial de Educação para Todos foi o marco definidor das ações e políticas públicas no final do século XX e início do século XXI, porém sabe-se que desde o ano de 1948, com a aprovação da Declaração Universal dos Direitos Humanos, os delineamentos da educação inclusiva já estavam sendo definidos (OLIVEIRA, 2004). Destaque também para o ano de 1981, que foi considerado o ano internacional da pessoa deficiente, onde se estabeleceram orientaçôes e diretrizes a serem seguidas pelos países. Os documentos internacionais são a resposta de grupos e movimentos organizados que lutam por melhorias da qualidade de vida das minorias, fundamentando a discussão da educação para todos e da igualdade de oportunidades (OLIVEIRA, 2005).

Dentre as inúmeras declarações e programas internacionais com ênfase no processo educacional, a Declaração de Salamanca é a que mais se destacou diante da realidade escolar e foi por meio de reunião e discussão de muitos países sobre a Educação para Todos, na cidade de Salamanca, na Espanha, que a Linha de Ação sobre necessidades educativas especiais, em 1994, foi aprovada. Essa declaração traz documentos que irão permear-se na "integração e no reconhecimento das necessidades de ação para conseguir 'escola para todos'” (DECLARAÇÃO DE SALAMANCA, 1994, p. 5), ou seja, propóe uma instituição que inclua todos, independentemente das suas diferentes necessidades, focando na aprendizagem desse aluno.

A Declaração de Salamanca defende uma escola integradora para crianças, jovens e adultos, dando ênfase nas diferenças de todos e usando essa diferença para o aprendizado do indivíduo.

Com o apoio dos governos, ela pretende: priorizar a política orçamentária, visando a melhoria de seus sistemas educativos; adotar o princípio da educação integrada; incentivar intercâmbios com países com experiência em escolas integradoras; criar mecanismos de planejamento, supervisão e avaliação do ensino de crianças e adultos com necessidades educativas especiais; facilitar a participação de pais, comunidade e organizaçóes de pessoas 
com deficiência no planejamento e no processo de tomada de decisóes; programa de formação de professores voltados para atender às necessidades educativas especiais nas escolas integradoras. As medidas apontadas são necessárias e fundamentais para melhorar a educação nos países que assinaram a Declaração de Salamanca, porém deve-se pensar nas condiçóes e na realidade de cada instituição. Quanto ao Brasil, por tratar-se de um país continental, essas medidas não poderiam ser iguais, o que acaba causando um problema, pois privilegiam apenas algumas instituiçôes, e a educação do país não caminha (DECLARAÇÃO DE SALAMANCA, 1994).

Diante da perspectiva internacional, constatamos que as políticas públicas são de suma importância na ampliação da visibilidade do deficiente, elas devem assegurar oportunidades educacionais, programas de esporte e lazer, etc. Porém, elas ainda não garantem a mudança de pré-concepçóes que já estão historicamente impregnadas na sociedade (OLIVEIRA, 2005). Hoje, ainda encontramos algumas dificuldades diante da realidade da inclusão, todavia o que se percebe é um desvio de foco da verdadeira problemática do processo. Os órgãos responsáveis pelos sistemas de ensino estadual, nacional e internacional fogem de suas responsabilidades, estimulando discussóes de caráter idealista, que fogem da realidade, chegando ao senso comum para justificar suas falhas no processo educacional (CARVALHO e TURECK, 2006).

O surgimento e fortalecimento do movimento das pessoas com deficiências ocorreram no Brasil no final da década de 1970 e início de 1980, contando com quatro fatores:

[N]ecessidades objetivas possibilitaram a tomada de consciência de uma parcela das próprias pessoas com deficiência no sentido de travarem lutas na defesa de seus direitos; a conjuntura nacional favorável, em que movimentos políticos e sociais lutavam contra a Ditadura Militar, na busca da redemocratização, da participação e da garantia de bens materiais; a mobilização internacional do segmento das pessoas com deficiência forçando uma conjuntura favorável em torno desta problemática social; um certo estimulo do governo brasileiro que não via nesse movimento nenhuma ameaça política ideológica. (ROSA e BORBA, 2006, p. 182)

É importante ressaltar que todos os seres humanos nascem livres e iguais em dignidade e direitos, devendo ser respeitados sem qualquer distinção. $\mathrm{O}$ direito de igualdade de todos os cidadãos corresponde ao art. $5^{\circ}$ 
da Constituição Federal Brasileira, vislumbrando a inclusão social das pessoas com necessidades especiais. Dessa forma, leis, programas, políticas, açôes governamentais vão surgindo no intuito de incluir, integrar e mudar a posição da pessoa com deficiência perante a sociedade. A Lei n. 7.853, de 24 de outubro de 1989, enfatiza o apoio às pessoas com necessidades especiais, objetivando afastar discriminaçóes e preconceitos de qualquer espécie. Vale destacar que tanto as autoridades governamentais quanto as entidades privadas devem proporcionar açôes capazes de eliminar preconceitos e discriminaçôes, promovendo a integração social do deficiente, como, por exemplo, educação, emprego, transporte e todos os outros direitos.

A Lei Federal n. 7.853/89, que é regulamentada pelo Decreto n. 3.298/99, propóe a inclusão (matrícula) de pessoas com deficiência no sistema de ensino regular, ou seja, aderir às escolas públicas e particulares aqueles que são capazes de integrarem-se às condiçóes dessas instituiçóes, compartilhando os benefícios conferidos aos outros educandos. Consequentemente, esse aluno terá acesso à educação profissional oferecida em seu nível básico, técnico e tecnológico, possibilitando seu ingresso no mercado de trabalho.

$\mathrm{O}$ artigo 203, inc. IV da Constituição Federal Brasileira, propôe habilitação e reabilitação profissional das pessoas com necessidades especiais, bem como a promoção de sua integração à vida comunitária. Uma pessoa deficiente é habilitada quando conclui o curso de educação profissional básico, técnico, tecnológico ou superior em uma instituição legalizada pelo Ministério da Educação. O Decreto n. 6.571, de 17 de setembro de 2008, dispóe sobre o atendimento educacional especializado e diz que é de reponsabilidade da Uniâo o apoio técnico e financeiro aos sistemas públicos de ensino, com a finalidade de ampliar a oferta do atendimento educacional.

Além das dificuldades para a inclusão dos deficientes na educação, no mercado de trabalho, etc., os indivíduos que possuem algum tipo de deficiência ainda sofrem com a falta de condiçóes para exercer o direito à locomoção e à informaçáo. Para assegurar esses direitos, entra em vigor no dia 19 de dezembro de 2000, a Lei Federal n. 10.098, regulamentada pelo Decreto n. 3.298/99, que estabelece benefícios de acessibilidade, como vias públicas, espaços livres, estacionamentos, construçóes, transportes, ampliaçóes e reformas de edifícios de uso público coletivo ou privado, que garantem o direito de ir e vir das pessoas com necessidades especiais.

De forma geral, é necessário que haja o cumprimento das leis relacionadas às pessoas com deficiência para que haja a eliminaçáo e/ou 
prevenção de preconceitos e discriminaçóes com objetivos de promover sua inclusão à sociedade, sua autossuficiência, vida independente e condiçóes igualitárias. Percebemos, assim, que os direitos humanos ainda são negados aos deficientes. Portanto, a sociedade deve incluir e proporcionar maior acessibilidade a esses sujeitos por meio de programas efetivos, políticas e leis que propiciem a igualdade de direitos entre os seres humanos, afinal as pessoas com deficiência são indivíduos socialmente inseridos, com os mesmos direitos que todos.

Os documentos citados elencam os direitos sociais e a individualidade com um objetivo forte, a educação para todos. Contudo, na sociedade individualista em que estamos inseridos, esse objetivo pode tornar-se utópico, devido às grandes diferenças sociais que existem dentro da própria instituição escolar. Com o apoio dessas leis, transformar a escola e o universo escolar fica um pouco mais fácil, pois elas instigam e incentivam não só alunos como também o complexo escolar que busca a melhoria de sua instituição. Esses documentos e orientaçóes significam uma maior visibilidade da juventude deficiente e dos problemas que eles enfrentam, refletindo também no campo da Educação Física, que, a partir da década de 1980, no Brasil, intensifica a produção teórica e o interesse por essa temática (OLIVEIRA, 2005).

\section{Inclusão: desafio para os sistemas educacionais}

Apoiando-nos em Tiballi (2003, p. 207), descobrimos que, para a escola se realizar diante dos seus três elementos fundamentais (aluno, professor e conhecimento) e cumprir sua tarefa de garantir a todos o acesso e a permanência no processo de escolarização, basta que

1. sejam garantidas às escolas as condiçóes institucionais e materiais necessárias para o funcionamento; 2 seja propiciada ao professor a qualificação profissional que possibilita distinguir e trabalhar pedagogicamente as diferentes formas de aprender que os alunos apresentam em uma mesma sala de aula; 3. seja garantida a todos os alunos a formação intelectual, ética e cultural que se dá por meio do conhecimento.

Diante dessa realidade, um grande desafio da inclusão se apresenta: transformar a educação para atender essa população diversificada, eliminando barreiras que limitam a aprendizagem e participação dos alunos. Contudo, 
esse ensino deve sempre pautar-se na educação de qualidade, que tenha igualdade de oportunidades a todos, mediante suas necessidades (MEC, 2005). Assim, a educaçáo inclusiva deve considerar que

[...] a ênfase está em desenvolver uma educação que valorize e respeite às diferenças, vendo-as como uma oportunidade para otimizar o desenvolvimento social e pessoal e para enriquecer os processos de aprendizagem. (MEC, 2005, p. 10)

As barreiras existentes no momento da prática inclusiva são muitas. $\mathrm{O}$ Ministério da Educação, ao elaborar os Ensaios Pedagógicos: Construindo Escolas Inclusivas, pontua três grandes barreiras: o das concepções e atividades, que busca a aceitação, o respeito e a valorização das diferenças por toda a sociedade; a segunda, que é das políticas públicas, que procura programas econômicos e sociais como apoio, inclusão, desde a educação infantil, possibilidade para os alunos concluírem a educação básica, reforma de currículo e apoio na formação profissional para escolas inclusivas; a terceira e última barreira aponta as práticas educacionais, que precisam de maior participação da comunidade na escola, escolas mais amigáveis, materiais didáticos para facilitar a aprendizagem do aluno e procedimentos mais flexíveis de métodos de avaliação (MEC, 2005). Essas consideraçôes do Ministério da Educação são válidas e tangem a mudança de atitudes da escola, da comunidade e do órgão responsável (o Estado). Sem essas mudanças, pouco pode ser feito perante a inclusão escolar, pois esta depende exclusivamente de seus contribuintes para manter-se em funcionamento (alunos, comunidade escolar e Estado).

Para garantir a operacionalização do ensino de alunos com deficiência, é necessária a qualificação do professor, contudo seria mais coerente dar ênfase na formação inicial e continuada desses profissionais para que eles possam atender às necessidades educacionais de todos os alunos, na inclusão ou mesmo no ensino regular (MANTOAN, s/d).

Ainda, quanto à formação dos professores no olhar da inclusão, sabe-se que existem diversos meios de capacitar esses profissionais, como pós-graduações, cursos de especialização e cursos preparatórios para a inclusão. Porém, Mantoan (s/d) defende que a formação dos professores é construída dentro das escolas, à medida que os problemas de aprendizagem dos alunos, com ou sem deficiência, aparecem. Trata-se de uma nova formação, que 
aprimora o que o professor já tem como conhecimento. Assim, esse profissional deve apoiar-se em todas as instâncias para melhorar seu trabalho pedagógico, seja em faculdades, especializaçôes, pós-graduações, ou mesmo dentro das salas de aula, que são verdadeiros espaços de aprendizado.

Encontramos, ainda, políticas que visam formar professores, não objetivando apenas sua formação, mas sua capacitação, profissionalização, treinamento e reciclagem, pois o interesse não está em uma formação integral e, sim, em um treinamento para que o professor possa desempenhar sua função.

Retardou-se, dessa forma, a compreensão de que o significado da formação de professores é

[...] possibilitar meios e/ou subsídios para que o futuro professor possa se apropriar dos conhecimentos e das habilidades pedagógicas necessárias a uma qualificação que lhe permita ainda, ter clareza de que todos os sujeitos são possuidores de capacidades, as quais são determinadas pela quantidade e pela qualidade das experiências adquiridas ao longo de sua existência. Assim, o individuo se apropriará dos conhecimentos produzidos e acumulados historicamente, bem como terá condição de contribuir para a transformação do meio onde está inserido. (IACONO e SILVA, 2006, p. 94)

Segundo o Doc. 95 (1998) - A formação profissional em educação física/ciências do esporte: balanços e perspectivas/possibilidades (apud CHAVES e GAMBOA, 2003, p. 175), o currículo de formação profissional deve ter

a) [...] como eixo articulador do conhecimento a Prática; b) como objeto de estudo as problemáticas significativas [...], reconhecidas e elaboradas a partir da pratica social contextualizada - cuja intencionalidade é dar direção ao processo de formação humana; c) como categoria teórica central e como princípio educativo as relaçóes trabalho-educação; d) como categorias específicas os pares dialéticos: organização do processo de trabalho - trato com o conhecimento; Objetivos - avaliação; situaçóes didáticas tempo pedagógico e político necessário; Dinâmica curricular - normalização, legislação; Finalidades - aprendizagens sociais significativas; e) como filosofia a práxis.

Para Bueno (1999), a formação de professores e qualificação do ensino para crianças com necessidades educativas especiais envolve dois tipos de formação profissional: o mínimo de formação para professores do 
ensino regular e a formação de professores especializados nas diferentes necessidades educativas especiais. A qualidade deve ser o fator determinante de um trabalho pedagógico voltado para atender às pessoas com necessidades especiais; o profissional deve ter, além de conhecimentos sobre as especialidades dos alunos, aspectos "do 'saber', do 'saber fazer', do 'saber conviver' e do 'saber ser”" (IACONO e SILVA, 2006, p. 105).

Estabelecer políticas de formação de professores necessita uma compreensão da realidade social e educacional, levando em consideração os aspectos da inclusão escolar. Porém, existem muitos fatores que impedem a implementação de uma política ampla, gratuita e democrática na área da educação especial/inclusiva. De acordo com a concepção teórica aqui defendida, essa formação deve ser fundamentada em aspectos científicos e pedagógicos e baseada no materialismo histórico-dialético, que busca apreender a realidade histórica em sua totalidade e contradiçóes (IACONO e SILVA, 2006).

Para conseguirmos o acesso a essa educação para as pessoas com deficiências, será necessária uma reflexão sobre o quanto são influentes os horizontes instrucionais da educação brasileira, bem como novas alternativas de organização curricular, comprometidas com a formação de sujeitos críticos, reflexivos, instrumentalizados teoricamente e um novo significado de trabalho, com sujeitos ativos capazes de questionar e modificar situaçóes. Além disso, para que essa educação seja de qualidade, as pessoas com deficiência devem fazer parte de sua história. Todavia, diante da realidade, eles somam-se à classe trabalhadora de forma mais ampla (CARVALHO e TURECK, 2006).

Para além da consciência de cada indivíduo, a escola de qualidade necessita de um apoio psicológico ao docente, atualizaçóes nas metodologias individualizadas, acompanhamento do aluno com deficiência e orientação para os pais (TESSARO, 2005).

Apesar de existirem alguns educadores comprometidos com uma educação crítica, a instituição escolar encontra-se inserida na sociedade capitalista, que tem como objetivo preparar homens para viverem nessa sociedade, ou seja, para serem produtivos. Nesse tipo de organização social, a força de trabalho é colocada como uma mercadoria, dessa forma a pessoa com deficiência passa a ser considerada uma defeituosa, com menores condiçóes de satisfazer o mercado, sendo, assim, compreendida como menos produtiva. Esse preconceito e discriminação devem ser entendidos como decorrentes da lógica da organização social, que está preocupada com a obtenção de maior quantidade de lucro possível (CARVALHO e ORSO, 2006). 
Segundo a Política Nacional de Educação Especial (2007), o professor que atua na educação inclusiva deve ter como bases de sua formação conhecimentos gerais para o exercício da docência e conhecimentos específicos da área. Os sistemas de ensino devem

[...] organizar as condiçóes de acesso aos espaços, aos recursos pedagógicos e à comunicação que favoreçam a promoção da aprendizagem e a valorização das diferenças, de forma a atender as necessidades educacionais de todos os alunos. A acessibilidade deve ser assegurada mediante a eliminação de barreiras arquitetônicas, urbanísticas, na edificação - incluindo instalaçóes, equipamentos e mobiliários - e nos transportes escolares, bem como as barreiras nas comunicaçóes e informaçóes. (MEC, 2007, p. 12)

Dessa forma, podemos observar que a inclusão não é uma questão simples como parece, ela necessita de muitos cuidados e sofre influências de diversas instâncias. Incluir significa considerar a realidade como fator influente na organização escolar, pois a inclusão escolar busca sempre aprimorar o ensino e, consequentemente, buscar uma sociedade mais avançada. Os professores são fontes fundamentais na mudança de pensamento da escola, por isso devem ter como principal objetivo sua capacitação e qualificação com o intuito de proporcionar mudanças na escola e em seus alunos. No campo da Educação Física, a inclusão ainda tem muito a caminhar, pois, por se tratar de uma disciplina muitas vezes prática, o professor, na maioria das vezes, não sabe como agir.

\section{Inclusão e educação física}

A partir de 1920, o processo de escolarização da Educação Física começou a influenciar o projeto educacional e a elaboraçáo de um conjunto de leis para a implementação da prática obrigatória da disciplina nas escolas. Mas foi em 1925 que surgiu a primeira escola para formação de professores de Educação Física, que pertencia à Marinha e que utilizava métodos ginásticos, voltados para a formação militar. Contudo, essa prática de modalidades esportivas consolidou-se em 1940, quando as preocupaçóes eram com as performances atléticas, voltadas para fatores fisiológicos e físicos. Assim, as aulas de Educação Física passaram a ser desenvolvidas e planejadas a partir dos aspectos técnicos e desportivos. Dessa forma, a Educação Física Escolar 
baseava-se mais em parâmetros fisiológicos que pedagógicos (STEFANE e MIZUKAMI, 2002).

Foi durante o governo de Getúlio Vargas, em 1939, que as primeiras instituições de formação de professores de Educação Física no meio civil foram criadas. Essa formação dos profissionais era voltada para o técnico em detrimento do professor licenciado. Foi somente em 1968 que as matérias pedagógicas começaram a se inserir nos currículos dos cursos de Educação Física. Entretanto, o caráter técnico ainda permeava os processos formativos de professores. Nos anos 1980 é que esse debate começa a ser transferido para a esfera educacional. Esse rompimento com o modelo anterior com a adoção de diferentes vertentes propiciou, no final de 1980, um grande debate em torno do desportivo-fisiológico (STEFANE e MIZUKAMI, 2002).

A articulação de diferentes teorias (psicológicas, sociológicas, filosóficas) possibilitou a compreensão das múltiplas dimensóes do ser humano, necessárias para o processo de ensino-aprendizagem de cada indivíduo. Desse modo, surgem algumas abordagens, como a "psicomotora, construtivista, desenvolvimentista e crítica, que tentam romper com o modelo tecnicista, esportista e biologicista até então predominante na Educação Física Escolar e na formação de professores" (STEFANE e MIZUKAMI, 2002, p. 242). Essas abordagens, no meio escolar, só mudaram o discurso dos professores, não sendo incorporadas em processos formativos da docência. Vê-se, ainda, que não houve discussão aprofundada no ambiente escolar, não causando nenhum impacto sobre as práticas pedagógicas (STEFANE e MIZUKAMI, 2002).

Podemos afirmar que a Educação Física Adaptada surgiu na década de 1950 como sendo

[...] um programa diversificado de atividades desenvolvimentistas, jogos e ritmos adequado aos interesses, capacidades e limitaçóes de estudantes com deficiências que não podem se engajar com participação irrestrita, segura e bem sucedida em atividades vigorosas de um programa de Educação Física geral. (PEDRINELLI, 1994 apud SILVA; SOUSA E VIDAL, 2006, p. 153)

Contudo sabe-se que essas atitudes ainda são segregacionistas, pois trabalham entre as pessoas com deficiência. $\mathrm{O}$ paradigma que a inclusão defende é de que todos trabalhem juntos, deficientes ou não. $\mathrm{O}$ professor que trabalha nessa perspectiva deve repensar seus objetivos, métodos, funçóes sociais, tempo, espaço e conhecimento para incluir esses alunos com 
necessidades especiais nas atividades desenvolvidas nas aulas de Educação Física (SILVA; SOUSA; VIDAL, 2006). Com o objetivo de proporcionar aos alunos um avanço intectual, esse professor deve estar atento a todas as perspectivas e possibilidades com o intuito de melhorar sua atividade pedagógica, utilizando da integração dos indivíduos como mais um fator que possa possibilitar avanços.

$\mathrm{Na}$ Educação Física existem alguns problemas em estabelecer uma ação pedagógica de qualidade e coerente com a vivência do deficiente. Auxiliá-lo a buscar sua inserção ampla na sociedade, a permanência e o avanço na escola, para assim propiciar sua emancipação, é uma tarefa difícil, considerando todos os aspectos sócio-históricos e culturais que envolvem a pessoa com deficiência (OLIVEIRA, 2005). Devido à realidade escolar, muitas açóes pedagógicas dos professores tornam-se nulas, pois conseguir avanços sociais para as pessoas com deficiência não depende só da instituição escolar, e, sim, de todo um processo social.

O professor de Educação Física é um dos principais facilitadores no processo ensino-aprendizagem de habilidades motoras e esportivas dos alunos com ou sem deficiência e, enquanto ensina os conteúdos da sua disciplina, ainda transmite valores, normas, formas de pensar e comportar diante da realidade. Porém, o contato que cada profissional tem com os deficientes define sua forma de agir diante das dificuldades, professores que tiveram maior contato com pessoas com deficiência podem ter atitudes mais favoráveis. Esse contato com pessoas com deficiência é importante para a formação do professor, além de experiências práticas com conteúdos diversos da Educação Física e da Educação Física Adaptada.

Para que esse processo de inclusão da criança deficiente possa acontecer, é necessário superar o pensamento conservador sobre suas incapacidades, ou seja, superar a visão pessimista de que o deficiente não consegue desenvolver-se intelectualmente. Dessa forma, uma "escola inclusiva somente ocorrerá a partir do momento em que as crianças deficientes possam ter direito ao conhecimento" (OLIVEIRA, 2004, p. 224). A contribuição da Educação Física Escolar vem no sentido de transmitir e ensinar saberes constituídos relacionados às práticas corporais sistematizadas.

No objetivo de melhorar e desenvolver processos de mudança nos indivíduos e nas instituiçóes, Oliveira (2004) afirma que a pesquisa e o conhecimento científico são o caminho para avanços e orientaçóes na área acadêmica de Educação Física, propiciando o desenvolvimento desses processos de mudança. 
Assim, podemos observar que a inclusão social e mesmo escolar será efetivada, primeiramente, com a mudança de pensamento dos envolvidos no processo, pois não haverá mudança enquanto a sociedade não aceitar, entender e aprender a lidar com a diferença. $O$ professor é o ator principal nesse processo, pois é ele que, no início da formação educacional das crianças, forma seus "seguidores", transmite e produz conhecimento e consciência junto com os alunos. Ele nada é sem o apoio de sua instituição escolar, dessa forma não adiantará um professor engajado e comprometido com os valores sociais se não existir essa preocupação em sua escola. Juntamente com a escola e o professor, as famílias e a comunidade precisam estar focadas em um objetivo, que é ajudá-los na formação desses novos cidadãos, conscientes da sociedade em que vivem, das diferenças existentes e de como tudo isso pode influenciar cada um de nós.

\section{Conclusão}

Diante dos objetivos traçados nesta pesquisa, conseguimos apresentar, por meio da literatura, a importância da formação e capacitação dos profissionais que estão em contato direto com esse grupo específico, as pessoas com deficiência. A diferenciação ao ensinar, o atendimento a uma população diversificada e a garantia do apoio das instituiçóes escolares são alguns dos fatores que dificultam a inclusão escolar.

O professor, que é o foco neste estudo, mais especificamente o professor de Educação Física, precisa do apoio das escolas, no sentido de modernizá-las e reestruturá-las. Além disso, ele deve ajudar na mudança de pensamentos, em superar valores e princípios que caminham "contra" a inclusão, buscando mais conhecimentos para desenvolver uma prática de ensino que apoie as diferenças.

Constatamos o quão difícil é falar, pensar e discutir sobre inclusão da pessoa com deficiência, tanto no âmbito social quanto no educacional. O que sabemos é que essa é uma sociedade excludente e composta por excluídos, que afasta não só a pessoa com deficiência, mas todos que fogem do padrão de normalidade ditada pela sociedade.

Para que a inclusão saia do discurso, é preciso um compromisso político e financeiro com o melhoramento do sistema educacional, tendo como meta transformar esse ensino em um ensino de qualidade preparado para acolher os diferentes alunos, independentemente de serem deficientes ou não. Isso acontecerá com uma mudança de pensamento (conscientização) e 
a união de todos, alunos, professores, pais, comunidade escolar, na busca de uma escola de qualidade.

A inclusão educacional, muitas vezes, pode trazer medo a muitas instituiçóes, pois incluir significa mudar e toda mudança gera um receio em qualquer atitude a ser realizada, por isso a inclusão necessita de projetos verdadeiramente engajados no compromisso de transformar a escola. Mesmo tratando-se de pessoas com deficiência, náo se pode esquecer que a inclusão também quer trazer todos os excluídos para a instituição escolar, sejam eles de ordem social, cultural, racial ou mesmo religiosos.

A uniáo dos participantes da sociedade na busca de uma conscientização é um fator de suma importância, pois os elementos estão diretamente ligados e são dependentes uns dos outros para que a inclusão aconteça. Falando-se em inclusão educacional, não podemos deixar de enfatizar que a escola inclusiva necessita de mudanças para que ela aconteça, como adaptaçóes arquitetônicas, adequaçáo de conteúdos curriculares, preparaçáo de professores, alteraçóes de caráter metodológico, etc.

A forma como a inclusão escolar vem sendo desenhada leva-nos a acreditar que poucos têm sido os investimentos e o interesse com o bem- estar da pessoa com deficiência. Provavelmente, isso ocorra por interesses político-econômicos, que querem apenas cortar gastos. As atitudes têm sido contrárias ao que dizem nas leis. A inclusão escolar requer gastos com infraestrutura adequada, professores habilitados, escolas bem estruturadas, necessitando, assim, de investimentos de órgãos governamentais, ou mesmo não governamentais.

A ausência de informações na formação profissional para trabalhar com alunos com necessidades educativas especiais é um fator presente na ação pedagógica dos atuais professores. Diante disso, acreditamos que ainda há muito a ser estudado e realizado dentro da perspectiva inclusiva.

\section{Referências}

BRASIL. Constituição da República Federativa do Brasil. Brasília, DF: Senado Federal, 1988.

BUENO, J. G. S. Crianças com necessidades educativas especiais, política educacional e a formação de professores: geralistas ou especialistas? Revista Brasileira de Educaçâo Especial, v. 3, n. 5, set. 1999. 
CARVAlHO, A. R.; ORSO, P. J. As pessoas com deficiência e a lógica da organização do trabalho na sociedade capitalista. In: $A$ pessoa com deficiência na sociedade contemporânea: problematizando o debate. Cascavel: Edunioeste, 2006. p. 155-180.

CARVALHO, J. R.; TURECK, L. T. Z. Algumas reflexôes sobre a inclusão escolar de alunos com deficiência. In: SILVA, V. L. R. R.; IACONO, J. P. Pessoa com deficiência na sociedade contemporânea: problematizando o debate. Cascavel: Edunioeste, 2006. p. 63-90.

CHAVES, M.; GAMBOA, S.S. Prática de ensino: formação profissional e emancipação. Maceió: Edufal, 2003.

DECLARAÇÃO de Salamanca e linha de ação sobre necessidades educativas especiais. Brasília: Corde, 1994.

DEMO, P. Metodologia cientifica em ciências sociais. 3. ed. rev. e ampl. São Paulo: Atlas, 1995.

IACONO, J. P.; SILVA, L. A. Algumas reflexôes sobre a política de formação de professores para a Educação Especial/ Educação Inclusiva. In: A pessoa com deficiência na sociedade contemporânea: problematizando o debate. Cascavel: Edunioeste, 2006. p. 63-90.

JANNUZZI, G. Educação física adaptada. Revista Brasileira de Ciências do Esporte. Campinas, v. 25, n. 3, p. 7-160, maio 2004.

MANTOAN, M. T. E. Ensinando a turma toda: as diferenças na escola. Educação inclusiva. Disponível em: <http://intervox.nec.ufrj.br/ elizabet/ turma.htm>. Acesso em: 08 out. 2008.

MEC. SEESP. Ensaios pedagógicos: construindo escolas inclusivas. 1. ed. Brasília, 2005.

- Política Nacional de Educação Especial na Perspectiva da Educação Inclusiva. Documento elaborado pelo Grupo de Trabalho nomeado pela Portaria Ministerial n. 555, de 5 de junho de 2007, prorrogada pela Portaria n. 948 , de 09 de outubro de 2007.

MENDONÇA, A. F.; NUNES, H.P. Elaboração do projeto de pesquisa. In: MENDONÇA, A. F. et al. Metodologia Cientifica: guia para elaboração e 
apresentação de trabalhos acadêmicos. Goiânia/GO: Faculdade Alfa, 2003. p. 59-83.

; ROCHA, C. R. R.; NUNES, H. P. Trabalhos acadêmicos: planejamento, execução e avaliação. Goiânia/GO. Faculdade Alfa, 2008. p. 35-80.

OLIVEIRA, C. B. Adolescência, inclusão de deficientes e educação física. Revista Digital, Buenos Aires. n. 82, 2005.

. A inclusão da criança deficiente no contexto da educação para todos: uma preocupação da educação física. Revista estudos, v. 31, n. 1, Goiânia, 2004.

ROSA, E. R.; BORBA, V. Apontamentos sobre o movimento social das pessoas com deficiência no Brasil. In: SILVA, V. L. R. R.; IACONO, J. P. A pessoa com deficiência na sociedade contemporânea: problematizando o debate. Cascavel: Edunioeste, 2006. p. 181-216.

SILVA, R. H. R.; SOUSA, S. B.; VIDAL, M. H. C. Educação Física Escolar e Inclusão: desafios para uma prática concreta. Revista Solta a Voz, Goiânia/ UFG, v. 17, n. 2, p. 145-161, jul./dez. 2006.

SOARES, C. L. Notas sobre a educaçáo no corpo. Educar, n. 16, p. 43-60, Curitiba, 2000.

STEFANE, C. A.; MIZUKAMI, M. G. N. A formação inicial vista a partir do exercício profissional da docência: contribuições de professores de Educação Física. In: MIZUKAMI, M. G. N.; REALI, A. M. M. R. Formação de professores: práticas pedagógicas e escolas. São Carlos: EdUFSCar, 2002. p. 237-260.

TESSARO, N. S. Inclusão Escolar: concepções de professores e alunos da educaçâo regular e especial. São Paulo: Casa do Psicólogo, 2005. p. 28-82 e $155-178$.

TIBALLI, E.F.A. Estratégias de inclusão frente à diversidade social e cultural na escola. In: LISITA, V.M.S.S.; SOUSA, L.F.E.C.P. (Orgs). Politicas educacionais, práticas escolares e alternativas de inclusão escolar. Rio de Janeiro: DP\&A, 2003. p. 195-208. 